\title{
Differential kynurenine pathway metabolism in highly metastatic aggressive breast cancer subtypes: beyond IDO1- induced immunosuppression
}

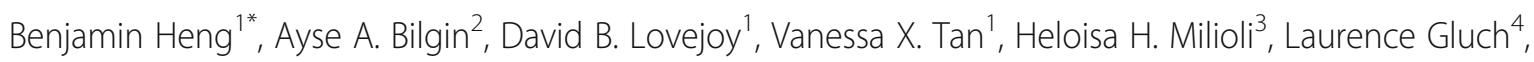
Sonia Bustamante ${ }^{5}$, Tharani Sabaretnam ${ }^{1}$ Pablo Moscato ${ }^{6}$, Chai K. Lim ${ }^{1+}$ and Gilles J. Guillemin ${ }^{1 *+}$ (ID

\begin{abstract}
Background: Immunotherapy has recently been proposed as a promising treatment to stop breast cancer (BrCa) progression and metastasis. However, there has been limited success in the treatment of $\mathrm{BrCa}$ with immune checkpoint inhibitors. This implies that BrCa tumors have other mechanisms to escape immune surveillance. While the kynurenine pathway (KP) is known to be a key player mediating tumor immune evasion and while there are several studies on the roles of the KP in cancer, little is known about KP involvement in $\mathrm{BrCa}$.

Methods: To understand how KP is regulated in $\mathrm{BrCa}$, we examined the KP profile in $\mathrm{BrCa}$ cell lines and clinical samples $(n=1997)$ that represent major subtypes of BrCa (luminal, HER2-enriched, and triple-negative (TN)). We carried out qPCR, western blot/immunohistochemistry, and ultra-high pressure liquid chromatography on these samples to quantify the KP enzyme gene, protein, and activity, respectively.

Results: We revealed that the KP is highly dysregulated in the HER2-enriched and TN BrCa subtype. Gene, protein expression, and KP metabolomic profiling have shown that the downstream KP enzymes KMO and KYNU are highly upregulated in the HER2-enriched and TN BrCa subtypes, leading to increased production of the potent immunosuppressive metabolites anthranilic acid (AA) and 3-hydroxylanthranilic acid (3HAA).
\end{abstract}

Conclusions: Our findings suggest that KMO and KYNU inhibitors may represent new promising therapeutic targets for BrCa. We also showed that KP metabolite profiling can be used as an accurate biomarker for BrCa subtyping, as we successfully discriminated TN BrCa from other BrCa subtypes.

Keywords: Kynurenine pathway, Breast cancer, Biomarker, Immune evasion, Tryptophan

\footnotetext{
*Correspondence: benjamin.heng@mq.edu.au; gilles.guillemin@mq.edu.au

${ }^{\dagger}$ Chai K Lim and Gilles J Guillemin are co-senior authors.

${ }^{1}$ Department of Biomedical Sciences, Faculty of Medicine and Health

Sciences, Macquarie University, Sydney, Australia

Full list of author information is available at the end of the article
}

C C The Author(s). 2020 Open Access This article is licensed under a Creative Commons Attribution 4.0 International License, which permits use, sharing, adaptation, distribution and reproduction in any medium or format, as long as you give appropriate credit to the original author(s) and the source, provide a link to the Creative Commons licence, and indicate if changes were made. The images or other third party material in this article are included in the article's Creative Commons licence, unless indicated otherwise in a credit line to the material. If material is not included in the article's Creative Commons licence and your intended use is not permitted by statutory regulation or exceeds the permitted use, you will need to obtain permission directly from the copyright holder. To view a copy of this licence, visit http://creativecommons.org/licenses/by/4.0/ The Creative Commons Public Domain Dedication waiver (http://creativecommons.org/publicdomain/zero/1.0/) applies to the data made available in this article, unless otherwise stated in a credit line to the data. 


\section{Background}

Breast cancer ( $\mathrm{BrCa})$ metastasis is the leading cause of cancer-related death in women $[1,2]$, indicating the need for new therapeutic targets. Immune checkpoint inhibitors have recently emerged as a new approach which enables immune cells to recognize and destroy cancer cells. In some metastatic tumors such as melanoma, immune checkpoint inhibitors have demonstrated significant therapeutic potential [3]. Despite BrCa often presenting with infiltrated immune cells [4-6], the efficacy of current immune checkpoint inhibitors in $\mathrm{BrCa}$ is far from optimal, suggesting the possibility of other dominant mechanisms that prevent or limit the immune response towards $\mathrm{BrCa}$.

Considering the strong evidence linking the kynurenine pathway (KP) to immunosuppression and tumor growth, the $\mathrm{KP}$ has been identified as a key immunotherapeutic cancer target [7, 8] (Fig. 1). Through induction of its first ratelimiting enzyme, indoleamine-2,3-dioxygenase 1 (IDO1), the $\mathrm{KP}$ has been associated with poorer prognosis in cancer patients $[9,10]$. Using a murine model, Uyttenhove et al. showed that a tumor with elevated IDO1 activity was not detected nor destroyed by tumor-specific host immune cells [11] - a phenomenon shown to result from tryptophan
(TRP) depletion by the IDO1-expressing tumor. Later studies also revealed that other bioactive KP metabolites may have immune-modulating properties. Fallarino et al. and Zaher et al. demonstrated that downstream KP metabolites such as 3-hydroxykynurenine (3HK), 3-hydroxyanthranilic acid (3HAA), and quinolinic acid can significantly inhibit $\mathrm{T}$ cell proliferation and induce $\mathrm{T}$ cell apoptosis $[12,13]$, thereby highlighting the important roles of other KP metabolites in affecting immune cells.

Despite the growing interest in the KP and cancers, there are limited studies examining the role of KP in human BrCa. Previous studies have shown elevated expression of IDO1 mRNA and protein in BrCa cells, as well as evidence of elevated IDO1 activity in $\mathrm{BrCa}$ patient sera compared to healthy controls [14-18]. Evidence also suggests that the KP may be involved in $\mathrm{BrCa}$ metastasis, as $\mathrm{BrCa}$ patients with lymph node metastasis showed increased regulatory $\mathrm{T}$ cells and a higher density of IDO1-expressing macrophages in their lymph nodes [19]. A separate study supported these findings, reporting that $\mathrm{BrCa}$ patients with bone metastases had elevated IDO1 activity in the sera, compared to patients without metastases [20]. Although there is strong accumulating evidence that IDO1 overactivation is involved in human

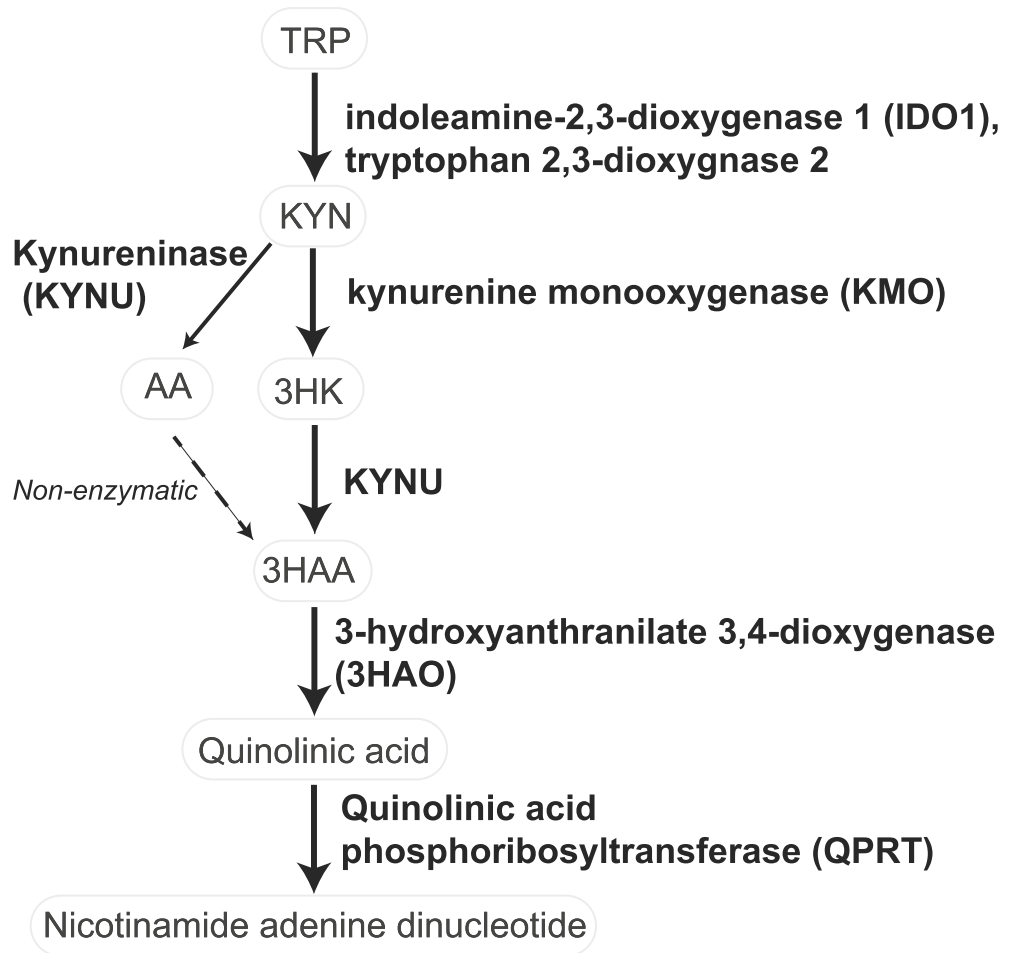

Fig. 1 A simplified diagram of the KP. Majority of TRP in the body is catabolized through KP to synthesize the vital energy cofactor, nicotinamide adenine dinucleotide. This pathway is frequently elevated in the inflammatory environment such as cancer and has been shown to promote immune evasion. This immune modulation results from the overactivation of IDO1/trytophan 2,3-dioxygenase 2 that leads to the depletion of local TRP, an essential amino acid for T cell proliferation, and production of bioactive metabolites (KYN, 3HK, AA, and 3HAA) that promotes selective apoptosis of tumor-targeting $T$ cells 
$\mathrm{BrCa}$, a significant limitation of these studies is that the $\mathrm{KP}$ profiling data has been limited to characterizing the degradation of TRP to its intermediate, kynurenine (KYN) by the enzymes IDO1 or tryptophan 2,3-dioxygenase 2 .

The potential roles of other KP enzymes and downstream KP metabolites remain totally unexplored in $\mathrm{BrCa}$. Considering that some of these are known to be immunomodulatory, this represents a considerable knowledge gap. Also, whether KP enzymes and metabolites differ between BrCa subtypes (i.e., luminal, HER2enriched, and triple-negative (TN)) and how these differences could be related to the differences in metastatic potential and disease aggressiveness is still unknown. Further, the KP enzyme kynurenine monooxygenase (KMO), active downstream of IDO1, has been shown to play a critical role in human hepatocellular carcinoma [21] and to be independent of IDO1 activity. Hence, it is important to examine how KP is regulated in each subtype to understand which KP enzyme is involved in the development and/or progression of $\mathrm{BrCa}$. The objectives of this study were to fully characterize the activity of the $\mathrm{KP}$ in each BrCa subtype and to investigate whether variations in serum KP parameters are associated with particular BrCa clinical subtypes.

\section{Methods}

\section{Human BrCa cell lines}

Human breast cancer cell lines representing the three major subtypes luminal $\mathrm{BrCa}$ cell lines (MCF7 and T47D), TN BrCa cell lines (MDA-MB-231, MDA-MB468, MDA-MB-157, and HBL100), and HER2-enriched $\mathrm{BrCa}$ cell line (SK-BR3) were cultured in RPMI (Life Technologies) containing $10 \%$ fetal calf serum and $1 \%$ antibiotic and antimycotic and were maintained at $37{ }^{\circ} \mathrm{C}$ with $5 \% \mathrm{CO}_{2}$ in a humidified atmosphere. Cell lines were authenticated by the Garvan Institute of Medical Research using short tandem repeat DNA profiling and were found to be $>93 \%$ concordant.

\section{The Molecular Taxonomy of Breast Cancer International Consortium (METABRIC) cohort}

The data used in this study consists of transcriptomic (cDNA microarray) information processed using the Illumina HT-12 v3 platform (Illumina_Human_WG-v3). Gene expression values of primary breast tumors were extracted from luminal (1140 samples), HER2-enriched (220 samples), and TN (199 samples) subtypes and from healthy control (HC) tissues (144 samples) [22].

\section{Patient cohort}

Two cohorts of BrCa clinical samples used in this study were sourced from the Victoria Cancer Biobank consortium, the Australian Breast Cancer Tissue Bank, or the
Strathfield Breast Centre. Cohort 1 comprised 506 serum samples from $408 \mathrm{BrCa}$ patients with luminal, HER2-enriched, and TN subtype and $98 \mathrm{HC}$. Cohort 2 consisted of 30 formalin-fixed tumor tissues from TN, HER2-enriched, or luminal subtype BrCa patients. As shown in Table 1, the groups were well distributed in both cohorts. The mean age differences between the $\mathrm{BrCa}$ groups were well controlled except for $\mathrm{HC}$ which was significantly younger $(p<0.0001)$.

All samples used in this study were from female patients who were diagnosed with primary $\mathrm{BrCa}$ as their first cancer event. Blood was collected before surgery, and tumor tissues were collected before chemotherapy treatment. Estrogen, progesterone receptor, and HER2 status were determined by qualified pathologists using immunohistochemistry. HC sera were sourced from the Australian Breast Cancer Tissue Bank.

\section{mRNA extraction and $\mathrm{qPCR}$}

To determine the gene expression along the KP, total mRNA was extracted with the RNeasy Mini Kit (Qiagen) according to the manufacturer's instructions. Following extractions, the quantity and quality of the total mRNA were measured using the Nanodrop 2000 (Thermo Fisher Scientific). For cDNA synthesis, $2 \mu \mathrm{g}$ of total mRNA was reverse transcribed with Superscript VILO cDNA Synthesis Kit (Thermo Fisher Scientific) according to the manufacturer's instructions. qPCR reactions were performed in a final volume of $10 \mu \mathrm{l}$ with each reaction mix containing $5 \mu \mathrm{l}$ Fast $\mathrm{SYBR}^{\bullet}$ green master mix, $5 \mu \mathrm{M}$ forward and reverse primers, and $125 \mathrm{ng}$ of cDNA template in the Viia7 (Thermo Fisher Scientific). The reaction was incubated at $95^{\circ} \mathrm{C}$ for $20 \mathrm{~s}$, then amplified for 40 cycles of $95^{\circ} \mathrm{C}$ for $1 \mathrm{~s}$ and $60^{\circ} \mathrm{C}$ for $20 \mathrm{~s}$. A melting curve was generated at the end of each reaction to confirm that only one product was formed. The mRNA expression levels of KP genes were normalized to tubulinbinding protein (TBP) and made relative to the untreated control condition using the $2^{-\Delta \Delta C}$ method. The sequences and efficiency of qPCR primers are generated in accordance with the MIQE PCR Guidelines [23] and are shown in Supplementary Table 1.

\section{Protein lysate preparation and western blot assay}

Cells were plated to achieve $70 \%$ confluency and treated for $48 \mathrm{~h}$ with IFN- $\gamma$ (specific activity, $1 \times 10^{7} \mathrm{IU} / \mathrm{mg}$; Miltenyi Biotech) or RPMI media as control. The cells were then lysed in a buffer containing $20 \mathrm{mM}$ Tris-HCL (pH 8.0), $137 \mathrm{mM} \mathrm{NaCl}, 1 \% \mathrm{NP} 40,10 \%$ glycerol, and $1 \times$ Protease Inhibitor Cocktail (Promega). Protein concentrations were measured by the Pierce ${ }^{\mathrm{TM}}$ BCA protein assay kit (Thermo Fisher Scientific). NuPAGE ${ }^{\oplus}$ sample reducing agent (Thermo Fisher Scientific) and Laemmli buffer (BioRad) were added to the samples and heated to 
Table 1 Demographic and clinical characteristics of cohorts 1 and 2

\begin{tabular}{|c|c|c|c|c|c|c|c|}
\hline \multirow[t]{2}{*}{ Subtype } & \multicolumn{4}{|l|}{ Cohort 1} & \multicolumn{3}{|l|}{ Cohort 2} \\
\hline & HC (\%) & Luminal (\%) & TN (\%) & HER2-enriched (\%) & Luminal (\%) & TN (\%) & HER2-enriched (\%) \\
\hline Total & 98 & 138 & 143 & 127 & 10 & 10 & 10 \\
\hline \multicolumn{8}{|l|}{ Age } \\
\hline Mean & 44.99 & 61.3 & 57.3 & 59.6 & 66 & 64.1 & 62.1 \\
\hline$<40$ & 33 (33.6) & $5(3.6)$ & $17(11.9)$ & $6(4.7)$ & $1(10)$ & 0 & 0 \\
\hline $40-49$ & $26(26.5)$ & $18(13.0)$ & $24(16.8)$ & 25 (19.6) & 0 & $1(10)$ & $2(20)$ \\
\hline $50-59$ & $24(24.5)$ & $43(31.2)$ & $37(25.9)$ & $34(26.8)$ & $3(30)$ & $2(20)$ & $3(30)$ \\
\hline $60-69$ & $14(14.3)$ & $37(26.8)$ & $31(21.7)$ & $31(24.4)$ & $1(10)$ & $3(30)$ & $3(30)$ \\
\hline$>70$ & $1(1.0)$ & $35(25.3)$ & $34(23.7)$ & $31(24.4)$ & $5(50)$ & $4(40)$ & $2(20)$ \\
\hline \multicolumn{8}{|c|}{ Histological grade } \\
\hline 1 & & $34(24.6)$ & 0 & 0 & 0 & 0 & 0 \\
\hline 2 & & $62(44.9)$ & $52(36.4)$ & $34(26.8)$ & 0 & 0 & 0 \\
\hline 3 & & $42(30.4)$ & $91(63.6)$ & $93(73.2)$ & $10(100)$ & $10(100)$ & $10(100)$ \\
\hline \multicolumn{8}{|l|}{ Tumor size } \\
\hline$<2 \mathrm{~cm}$ & & $58(42.0)$ & $68(47.6)$ & $43(33.8)$ & $2(20)$ & $2(20)$ & $1(10)$ \\
\hline $2.0-5.0 \mathrm{~cm}$ & & $57(41.3)$ & $72(50.3)$ & $65(51.2)$ & $5(50)$ & $8(80)$ & $8(80)$ \\
\hline$>5 \mathrm{~cm}$ & & $23(16.7)$ & $3(2.1)$ & $18(14.2)$ & $3(30)$ & 0 & $1(10)$ \\
\hline Not available & & 0 & 0 & $1(0.8)$ & 0 & 0 & 0 \\
\hline \multicolumn{8}{|l|}{ PR status } \\
\hline Positive & & $138(100)$ & $0(0)$ & $0(0)$ & $8(80)$ & $0(0)$ & $12(9.4)$ \\
\hline Negative & & $0(0)$ & $143(100)$ & $127(100)$ & $2(20)$ & $10(100)$ & 115 (90.6) \\
\hline \multicolumn{8}{|l|}{ HER2 IHC } \\
\hline Positive & & $119(86.2)$ & $0(0)$ & $12(9.4)$ & $0(0)$ & $0(0)$ & $10(100)$ \\
\hline Negative & & 19 (13.8) & $143(100)$ & 115 (90.6) & $10(100)$ & $10(100)$ & $0(0)$ \\
\hline
\end{tabular}

$70{ }^{\circ} \mathrm{C}$ for $10 \mathrm{~min}$. Denatured samples were transferred onto ice before separation by electrophoresis on a $\mathrm{kD}^{\mathrm{m}}$ Mini-PROTEAN ${ }^{\bullet}$ TGX protein gel (BioRad). The proteins were then transferred to nitrocellulose membranes and blocked with 5\% skim milk for an hour. Blots were probed overnight at $4{ }^{\circ} \mathrm{C}$ with primary antibodies: IDO1 (1:1000; clone: UMAB126, Origene), KMO (1:1000; LSBio), kynureninase (KYNU) (1:500; clone: OTI1H1, Origene), and actin (1:1000; Abcam). Secondary antimouse (1:10,000; Dako) and anti-rabbit (1:12,000; Dako) antibodies were incubated for its corresponding primary antibody for an hour before developing with Clarity ${ }^{\mathrm{mu}}$ Western ECL substrate (Bio-Rad).

\section{Quantification of KP metabolites}

Prior to analysis, $150 \mu \mathrm{l}$ of biological fluids was deproteinized with $10 \%(\mathrm{w} / \mathrm{v})$ trichloroacetic acid in equal proportions. Samples were incubated for $5 \mathrm{~min}$, vortexed, then centrifuged $\left(4^{\circ} \mathrm{C}\right)$ for $10 \mathrm{~min}$ at $12,000 \mathrm{rpm}$. The supernatant was then extracted and filtered with 0.22 $\mu \mathrm{m}$ syringe filters (Millex, Merck) ready for injection into the analyzers.
Concurrent quantification of TRP, KYN, 3HK, 3HAA, and AA was carried out as previously described [24]. Briefly, $20 \mu \mathrm{l}$ of the filtered extract was injected into the analyzer. Separation of metabolites was performed under a stable temperature of $38^{\circ} \mathrm{C}$ for $12 \mathrm{~min}$, using $0.1 \mathrm{mM}$ sodium acetate $(\mathrm{pH} 4.65)$ as the mobile phase, with an isocratic flow rate of 0.75 $\mathrm{ml} / \mathrm{min}$ in an Eclipse Plus C18 reverse-phase column $(2.1 \mathrm{~mm} \times 150 \mathrm{~mm}, 1.8 \mu \mathrm{m}$ particle size, Agilent). $3 \mathrm{HK}$ and KYN were detected using UV wavelength at 365 nM. TRP, 3HAA, and AA were detected using fluorescence intensity set at Ex/Em wavelength of 280/438 for TRP and 320/438 for 3HAA and AA. Mixed standards of all metabolites were used for a 6-point calibration curve in order to interpolate the quantity of the sample readout. Agilent OpenLAB CDS Chemstation (Edition C.01.04) was used to analyze the chromatogram. The inter- and intra-assay coefficient of variation is within the acceptable range of $3-7 \%$. Concentrations of KP metabolites in cell culture media were calculated by subtracting the values of pre- and post-treatment concentrations. 


\section{Immunohistochemistry and scoring of staining}

Formalin-fixed paraffin-embedded tissue sections $(8 \mu \mathrm{M})$ were purchased from the Victoria Cancer Biobank. The sections were deparaffinized and rehydrated through graded alcohols to water. Antigen retrieval was performed by boiling the de-paraffinized sections in specific buffers according to each antibody. After placing the slides onto a chamber stacker, they were rinsed thrice with a wash buffer (Dako). Endogenous peroxidase activity was blocked with a 10-min incubation of Dual Endogenous Enzyme-Blocking Reagent (Dako). Thereafter, the slides were rinsed with wash buffer (Dako) and blocked with 5\% BSA (Sigma Aldrich) in PBS-T (PBS with $0.2 \%$ Tween20) for $1 \mathrm{~h}$ at room temperature. The primary $\mathrm{KP}$ enzyme antibodies (IDO1 1:100 and KYNU 1:100 antibody as mentioned above in western blot; KMO, 1:100 (Sigma Aldrich) and isotype control antibody (IDO1 isotype control IgG1/clone DAK-GO1 (Dako), KMO isotype control rabbit IgG (Abcam), KYNU isotype control IgG2b/clone DAK-GO9 (Dako) were applied overnight at $4{ }^{\circ} \mathrm{C}$. After primary antibody incubation, the sections were washed and incubated for $1 \mathrm{~h}$ with a peroxidase-labeled secondary antibody specific for each primary antibody.

The slides were scored numerically by three blinded researchers, and a composite staining score was calculated based on two categories: (1) the percentage of tumor stained positive $(0=0 \%, 1=1-33 \%, 2=34-66 \%$, $3=\geq 66 \%)$ and (2) intensity of protein staining $(0,1,2$, 3). Differences in scores were adjudicated between the researchers to arrive at a final score.

\section{Statistical analysis and modeling}

Descriptive statistics were used to identify outliers, missing data, and normality of KP variables and demographics. Where needed, data normalization was performed prior to analysis. Exploratory data analysis involving multiple groups or case-control comparison was performed using one-way ANOVA and $t$ test, respectively. Differences in the expression/level of variables of interests were considered significant if $p<0.05$.

To develop an algorithm that can potentially discriminate the $\mathrm{BrCa}$ subtypes based on predictors (i.e., variables of interests identified during exploratory analysis), a supervised machine learning approach using various classification models was applied. These models included the Classification and Regression Tree, neural networks [25], support vector machines, discriminant analysis, and C5.0 decision tree [26, 27] that were previously described for a similar study design [24]. First, we randomly split the dataset into training (77\%) and test (23\%) sets. Then, an iterative model-building framework approach was used to find the best model for our aim. A classification model was considered successful when it had the highest predictive accuracy for specific subtype observations. In addition to accuracy, we calculated the classspecific lifts, sensitivity, and specificity of the models. To minimize the overfitting of the model, a 10 -fold cross-validation and pruning set at $75 \%$ were implemented during the analysis.

All statistical analyses were performed using the $R$ software (R Core team 2015), with the $R$ package [28] and illustrated with Prism 8 (GraphPad) and Excel. All classification modeling was developed using IBM SPSS Modeler (version 18.0, 2016).

\section{Results}

IDO1 expression and activity is predominately upregulated in TN and HER2-enriched BrCa subtype

Given the important role of KP (Fig. 1) in immunosuppression and tumor growth, we screened $\mathrm{BrCa}$ models for the first rate-limiting enzyme of the KP, IDO1, which is known to play a significant role in modulating immune response using the publicly available, large population-based METABRIC BrCa dataset. This analysis showed that IDO1 gene expression in $\mathrm{BrCa}$ tissue is upregulated in TN and HER2-enriched $\mathrm{BrCa}$ subtype compared to luminal $\mathrm{BrCa}$ and $\mathrm{HC}$ (Fig. 2a). This result was consistent with the serum KYN to TRP concentration ratio (K/T ratio) from cohort 1 showing increased IDO1 activity in both TN $(p<0.01)$ and HER2-enriched $(p<0.001)$ BrCa subtypes $(F(3,483)=1.531$, Fig. $2 b)$. Furthermore, assessing the levels of IDO1 protein expression in $\mathrm{BrCa}$ tissues from cohort 2 showed that IDO1 was highly expressed in TN and HER2-enriched BrCa subtypes $(F(2,27)=5.52$; Fig. 2c) but was absent (or minimally detected) in luminal $\mathrm{BrCa}$, results which were consistent with the serum KP metabolite profiles in cohort 1 .

To further extend these findings, we modeled a proinflammatory tumor microenvironment by exposing $\mathrm{BrCa}$ cell lines to the inflammatory cytokine IFN- $\gamma$, one of the most potent IDO1 inducers, at pathophysiologically relevant concentrations for up to $48 \mathrm{~h}$ and then assessed the effect on the KP profile. After $24 \mathrm{~h}$ exposure, IDO1 gene expression was again highest in the TN $\mathrm{BrCa}$ cell line followed by HER2-enriched cell line, SKBR3, then the luminal cell line, MCF7 (Fig. 2d). These results were also consistent with the METABRIC data. Interestingly, post-translational production of active IDO1 enzyme, which occurs by $48 \mathrm{~h}$ INF- $\gamma$ treatment, was indicated by markedly elevated $\mathrm{K} / \mathrm{T}$ ratio only in the TN cell lines, suggesting that IDO1 activity is only highly inducible in $\mathrm{TN}$ BrCa cells in a pro-inflammatory milieu (Fig. 2e and Supplementary Fig. 1A and D). 

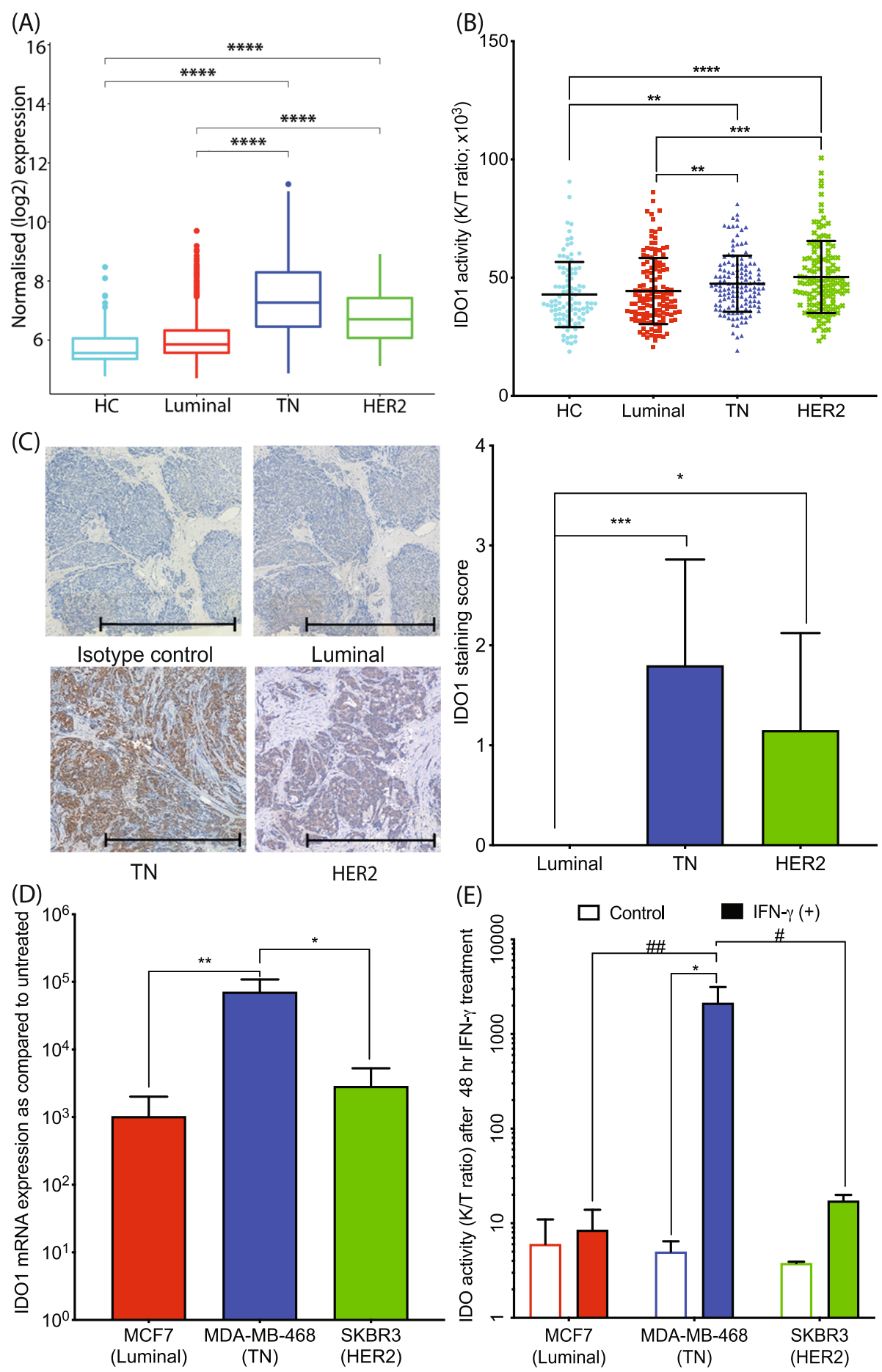

Fig. 2 IDO1 enzyme expression and activity in HC and various BrCa subtypes. a IDO1 mRNA log2-normalized expression level is significantly increased in TN ( $n=199)$ and HER2-enriched $(n=220)$ BrCa subtypes, compared to luminal $(n=1140)$ and healthy control $(n=144)$ tissues from the METABRIC dataset. $\mathbf{b}$ IDO1 activity (as reflected by the ratio of KYN to TRP concentration, $\mathrm{K} T$ ratio) is upregulated in $\mathrm{TN}(n=143)$ and HER2-enriched $(n=127)$ BrCa patient serum relative to HC $(n=98)$ and luminal $(n=138)$ BrCa patient sera. c IDO1 protein immunohistochemistry in BrCa tissues shows pronounced IDO1 staining in TN and HER2enriched BrCa subtypes. Representative images of IDO1 staining in BrCa tumor tissue subtypes with semi-quantification ( $n=10$ each subtype; scale bar, $1000 \mu \mathrm{M})$. $\mathbf{d}$ Induction of IDO1 mRNA is approximately 100-fold higher in TN cells relative to HER2 and luminal BrCa cells after $24 \mathrm{~h} \mathrm{IFN- \gamma}$ treatment $(n=3$, in triplicate). e Only TN BrCa cells show a marked translation of active IDO1 protein as judged by K/T ratio after $48 \mathrm{~h}$ IFN- $\gamma$ treatment $(n=3$, in triplicate). The error bars indicate the standard deviation from the triplicates of cell culture treatment. KP metabolite analysis was performed using uHPLC. ${ }^{*} p<0.05 ;{ }^{*} p<0.01$; ${ }^{* * *} p<0.001 ;{ }^{* * * *} p<0.0001$ 


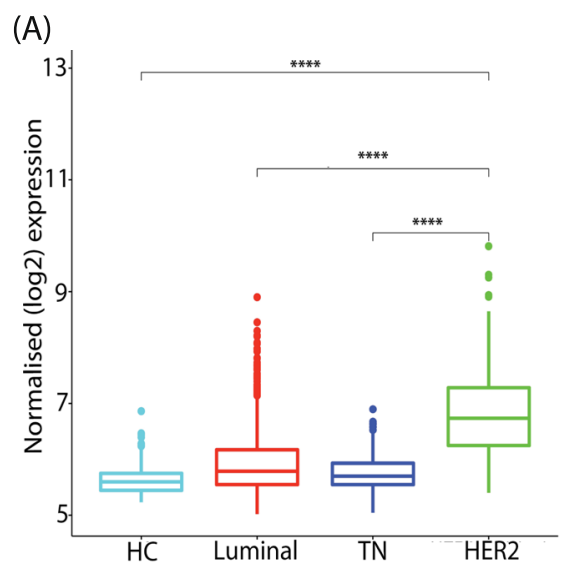

(C)
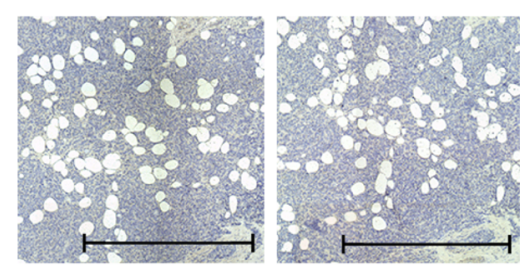

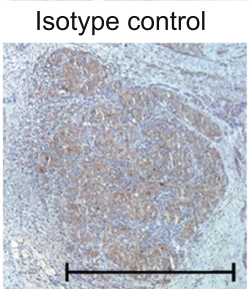

TN

(D)
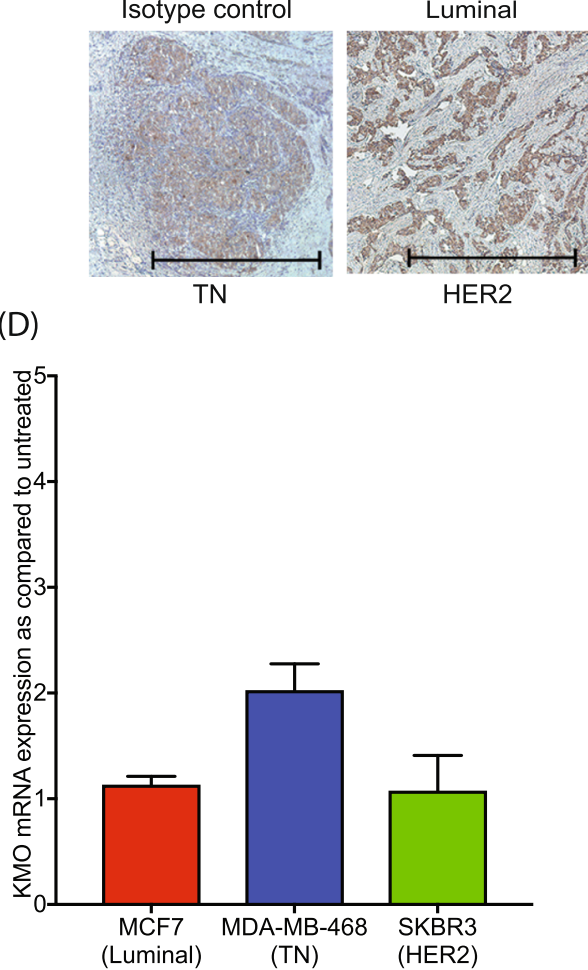

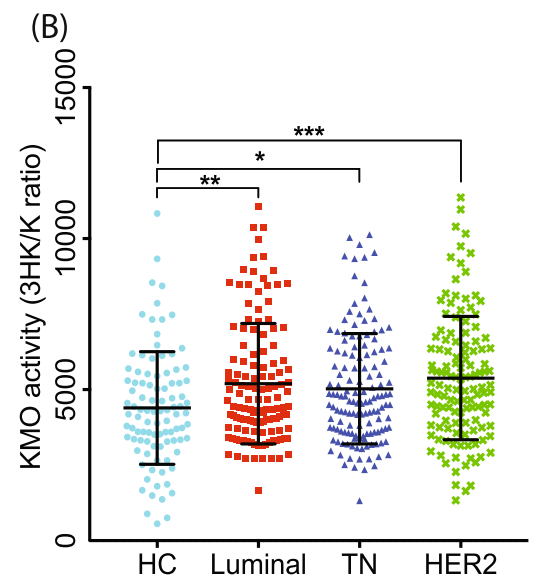

(B)

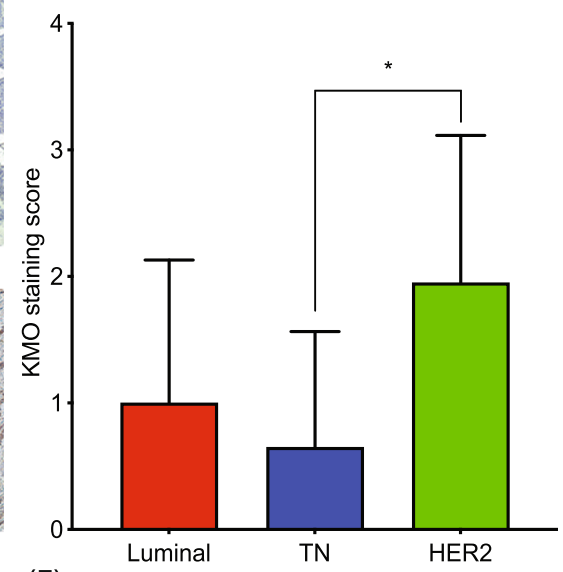

(E)

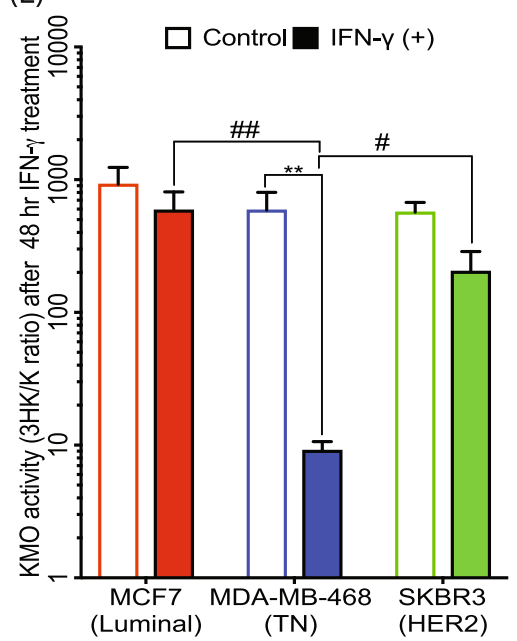

Fig. $3 \mathrm{KMO}$ enzyme expression and activity in $\mathrm{HC}$ and various BrCa subtypes. a All BrCa tissues expressed KMO mRNA more highly than the HC, with HER2-enriched tissues showing most expression in the METABRIC dataset. b KMO activity (as reflected by the ratio of 3HK to KYN concentration, 3HK/K ratio) is upregulated in all $\mathrm{BrCa}$ patient sera relative to $\mathrm{HC}$, with HER2-enriched $\mathrm{BrCa}$ patient serum showing the highest $\mathrm{KMO}$ activity. c KMO protein immunohistochemistry in $\mathrm{BrCa}$ tissues shows that $\mathrm{KMO}$ expression is highest in the HER2-enriched BrCa subtype. Representative images of KMO staining in BrCa tumor tissue subtypes with semi-quantification ( $n=10$ each subtype; scale bar, $1000 \mu \mathrm{M}$ ). $\mathbf{d}$ KMO mRNA expression increased only in TN BrCa cells (2-fold change) after $24 \mathrm{~h} \mathrm{IFN-} \gamma$ treatment ( $n=3$, in triplicate). e The low $3 \mathrm{HK} / \mathrm{KYN}$ ratio observed in the TN BrCa cell lines could potentially be due to the elevated production of substrate KYN induced by IFN- $y$ treatment. KP metabolite analysis was performed using UHPLC in BrCa cell supernatants and cell pellets ( $n=3$, in triplicate) or in human plasma samples, HC $(n=98)$, luminal $(n=138)$, TN $(n=143)$, and HER2-enriched ( $n=127)$. The error bars in $\mathbf{d}$ and $\mathbf{e}$ indicate the standard deviation from the triplicates of cell culture treatment. ${ }^{*} p<0.05 ;{ }^{* *} p<0.01 ;{ }^{* * *} p<0.001 ;{ }^{* * * *} p<0.0001$ 


\section{KMO activity markedly upregulated in HER2-enriched BrCa subtype}

KYN sits at a branching point of the KP where it can be catabolized into three different intermediates, 3HK, kynurenic acid, or AA by the enzymatic activity of KMO, kynurenine aminotransferase (KATs), or KYNU, respectively. In the METABRIC samples, all BrCa tissue subtypes had higher KMO gene expression levels compared to $\mathrm{HC}$ with the highest expression found in the HER2-enriched BrCa subtype (Fig. 3a). The KP metabolite profile of cohort 1 corroborates with the public data, as serum $3 \mathrm{HK} / \mathrm{KYN}$ ratio, a measure of active KMO enzyme activity, was also highest in the HER2-enriched subtype with all other $\mathrm{BrCa}$ subtypes showing elevated KMO relative to the $\mathrm{HC}$ group $(F(3,491)=0.5707$, Fig. 3b). Immunohistochemical KMO staining was also highest in HER2-enriched $\mathrm{BrCa}$ tissues in cohort $2(F(2$, 27) = 0.4258; Fig. 3c).

As $\mathrm{KMO}$ is inducible during inflammation [29], we also examined KMO expression and activity in different $\mathrm{BrCa}$ cell lines after IFN- $\gamma$ stimulation for 24 or $48 \mathrm{~h}$. KMO mRNA was constitutively expressed with no significant differences between luminal and HER2enriched cell lines (Fig. 3d). In TN BrCa cells, a twofold increase in KMO mRNA was observed. However, $\mathrm{KP}$ metabolite concentrations measured after $48 \mathrm{~h}$ of IFN- $\gamma$ treatment showed that the $3 \mathrm{HK} / \mathrm{KYN}$ ratio was significantly reduced in TN cells $(p<0.01)$ (Fig. 3e). The $3 \mathrm{HK} / \mathrm{KYN}$ ratio, while indicative of KMO activity, is also responsive to $\mathrm{KYN}$ production or $3 \mathrm{HK}$ consumption. As noted above in Fig. 2e, IFN- $\gamma$ treatment dramatically increased the $\mathrm{K} / \mathrm{T}$ ratio, i.e., $\mathrm{KYN}$ production, in TN cells by inducing IDO1, which may explain these results. The KP enzyme profile of other $\mathrm{BrCa}$ cell lines was similar by subtype to the results described above (Supplementary Fig. 1B and E).

\section{KYNU is highly upregulated in HER2-enriched serum samples with preferential de novo AA synthesis} The KYNU mRNA expression levels in the METABRIC data were highest in HER2-enriched followed by TN subtype relative to luminal and controls (Fig. 4a). Assessing cohort 2 by immunohistochemistry showed that the highest expression of KYNU protein was found in TN, rather than HER2-enriched $\mathrm{BrCa}$ tissue (Fig. 4b). This discrepancy between the cohorts could be due to the distribution of sample size in various grades of $\mathrm{BrCa}$. The TN and HER2-enriched samples used in cohort 2 were all grade 3 while the METABRIC cohort consisted of samples from all stages. The KYNU enzyme is located at two different points in the KP and catabolizes two different substrates, KYN and $3 \mathrm{HK}$, leading to the production of AA and 3HAA, respectively (Fig. 1). KP metabolite analysis of cohort 1 plasma showed a much higher AA/KYN ratio in HER2 samples, indicating that KYNU activity is highest in this subtype $(F(3,467)=$ 17.12, Fig. 5a) and also highlighted that the production of AA and not 3HAA is the preferred KP sub-branch. As $\mathrm{AA} / \mathrm{KYN}$ and $3 \mathrm{HAA} / 3 \mathrm{HK}$ ratios are interdependent (AA is produced from KYN by KYNU in one subbranch but $3 \mathrm{HK}$ is converted to $3 \mathrm{HAA}$ by $\mathrm{KYNU}$ in the other sub-branch), the AA/KYN ratio should show an inverse relationship with the $3 \mathrm{HAA} / 3 \mathrm{HK}$ ratio. This was also observed in our clinical plasma samples (Fig. 5b). Possible explanations of the marked difference between AA and 3HAA production among the BrCa subtype include the production of KYN by activated IDO1 in these patients. This could potentially lead to the saturation of KYNU upstream of the pathway by KYN. While increasing AA, KYNU saturation would limit the conversion of $3 \mathrm{HK}$ to $3 \mathrm{HAA}$. Additionally, the failure of an oxidationreduction reaction in the system to convert the AA into 3HAA could also lead to this discrepancy [30]. Another
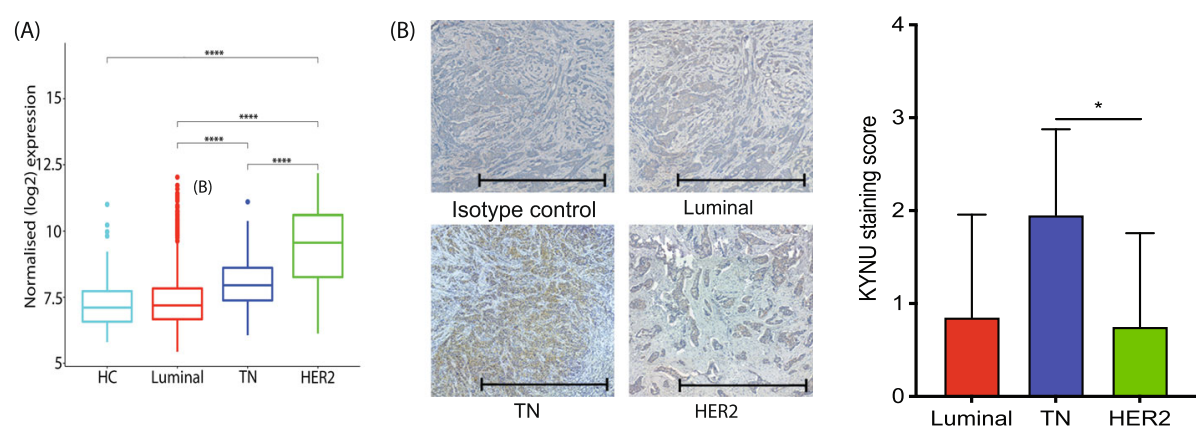

Fig. $4 \mathrm{KYNU}$ enzyme expression and activity in $\mathrm{HC}$ and various BrCa subtypes. a KYNU mRNA expression level is most significantly increased in HER2-enriched BrCa patient tumor tissues from the METABRIC dataset. b KYNU protein immunohistochemistry in BrCa tissues shows that KYNU expression is highest in the TN BrCa subtype. Representative images of KYNU staining in BrCa tumor tissue subtypes are shown with semiquantification ( $n=10$ each subtype; scale bar, $1000 \mu \mathrm{M}$ ) 

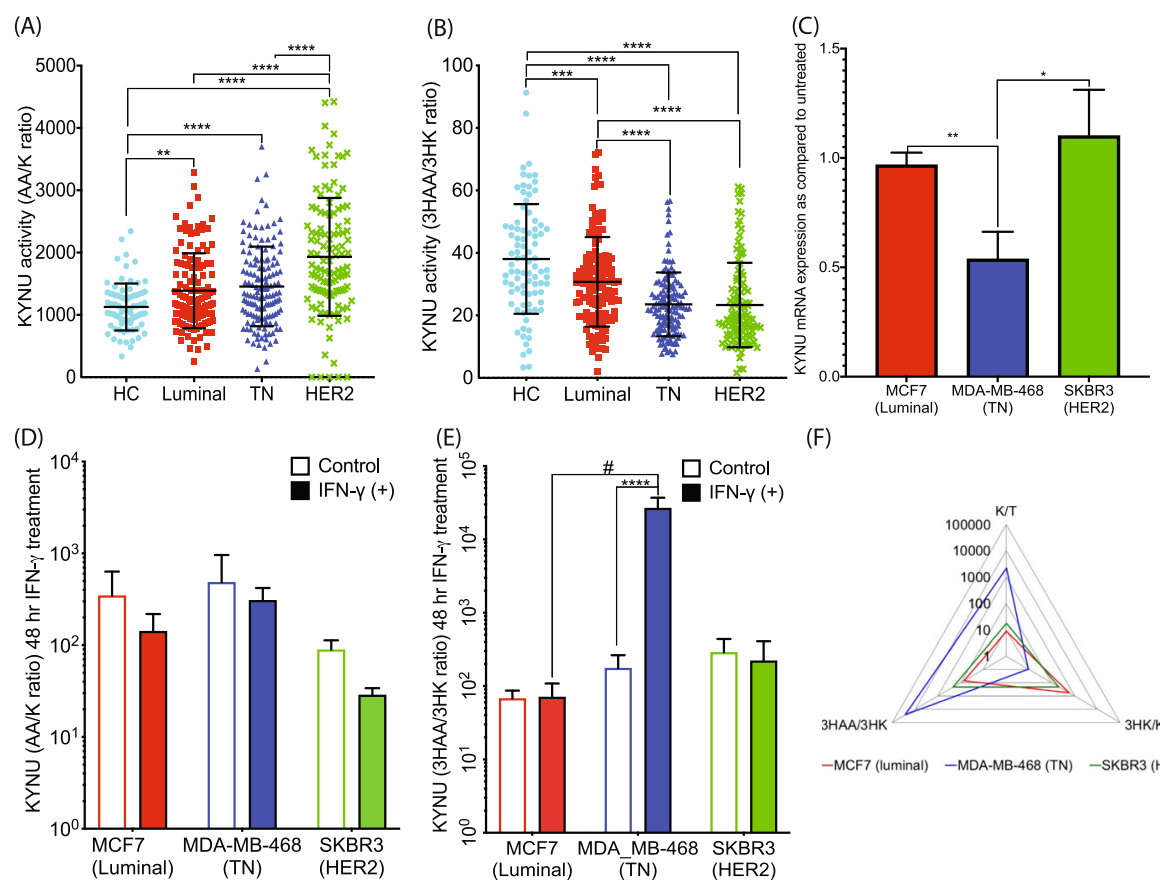

(F)

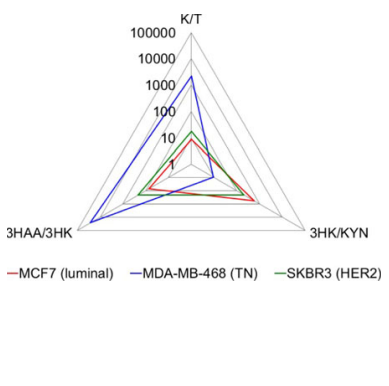

Fig. $5 \mathrm{KYNU}$ is dysregulated in HER2-enriched and TN BrCa subtype. a KYNU activity along the minor KP sub-branch leading to AA (as reflected by the $\mathrm{AA} / \mathrm{K}$ ratio) is upregulated in all $\mathrm{BrCa}$ patient sera relative to $\mathrm{HC}$, with $\mathrm{HER}$-enriched BrCa patient serum showing the highest $\mathrm{KYNU}$ activity in this subbranch. $\mathbf{b}$ KYNU activity along the major KP sub-branch that leads to $3 \mathrm{HAA}$ (as reflected by the 3HAA $3 \mathrm{HK}$ ratio) is downregulated in all BrCa patient sera relative to $\mathrm{HC}$, with HER2-enriched BrCa patient serum showing the lowest KYNU activity in this sub-branch. c KYNU mRNA expression is not induced in TN BrCa cells after $24 \mathrm{~h} \mathrm{IFN-} \gamma$ treatment ( $n=3$, in triplicates) relative to untreated cells. $\mathbf{d} \mathrm{KYNU}$ activity along the minor KP sub-branch that

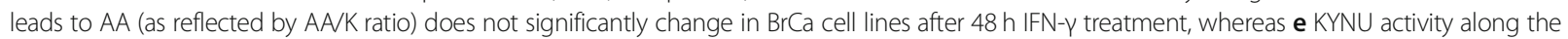
major KP sub-branch leading to 3HAA (as reflected by 3HAA/K ratio) is significantly upregulated in TN BrCa cells lines after $48 \mathrm{~h} \mathrm{IFN-} \gamma$ treatment. $\mathbf{f}$ Radar chart of KP enzyme activity after IFN- $\gamma$ treatment (as reflected by various KP metabolite ratios) shows the distinct pattern of KP dysregulation in TN BrCa cells, relative to luminal and HER2-enriched BrCa cells (increased IDO1 and major sub-branch KYNU activity) which, in turn, leads to the preferential production of the immune-suppressive metabolite 3HAA. KP metabolite analysis was performed using uHPLC in BrCa cell supernatants and cell pellets ( $n=3$, in triplicate) or in human plasma samples, HC $(n=98)$, luminal $(n=138)$, TN $(n=143)$, and HER2-enriched $(n=127)$. The error bars in $\mathbf{c}-\mathbf{e}$ indicate the standard deviation from the triplicates of cell culture treatment. ${ }^{*} p<0.05 ;{ }^{* *} p<0.01 ;{ }^{* *} p<0.001 ;{ }^{* * *} p<0.0001$

potential explanation leading to a high concentration of $\mathrm{AA}$ in the sera is the availability of cofactors such as metal ions and vitamin B6 to KYNU. Deficiency in one of these cofactors has been shown to reduce the activity of the enzyme to produce AA [31].

\section{Substrate-dependent KP activity leads to de novo 3HAA synthesis in TN BrCa cell line}

TN BrCa cell lines treated with IFN- $\gamma$ did not show a significant increase in KYNU mRNA expression (Fig. 5c and Supplementary Fig. 1C) or in the AA/KYN ratio (Fig. 5d and Supplementary Fig. 1F). Despite these observations, the $3 \mathrm{HAA} / 3 \mathrm{HK}$ ratio was highest in $\mathrm{TN} \mathrm{BrCa}$ cells compared to luminal and HER2-enriched subtype cells (Fig. 5e and Supplementary Fig. 1G) implying an enhanced KYNU activity. The concentration of the 3HAA metabolite increased to $4860 \mathrm{nM}$ compared to 17 $\mathrm{nM}$ in non-IFN- $\gamma$-treated TN cells (a 286-fold increase). Potential explanations of these results include a higher non-enzymatic conversion of AA to 3HAA or the increased availability of KYN substrate resulting from hyperactivation of IDO1 due to IFN- $\gamma$ treatment as depicted in the radar chart (Fig. 5f).

\section{Differential KP profiling discriminates TN from non-TN BrCa cases}

Using a supervised machine learning approach, we identified that the most important predictors of $\mathrm{TN} \mathrm{BrCa}$ were AA/KYN (0.34), age (0.29), 3HAA/AA (0.14), K/T ratio (0.08), TRP $(0.08)$, and KYN (0.07) in our clinical cohort 1 dataset. We then applied classification modeling to KP metabolite concentration and KP enzyme ratios in the $\mathrm{BrCa}$ subtypes and control sera. Among the classification models, the C5.0 decision tree was found to have the best accuracy for each $\mathrm{BrCa}$ subtype and $\mathrm{HC}$, ranging from $36.7 \%$ (control) to $66.4 \%$ (TN). These predictors performed poorly in discriminating $\mathrm{HC}$ but had better accuracy for TN.

We then re-trained our training set using $\mathrm{BrCa}$ without controls and classified the subtypes into $\mathrm{TN}$ and 


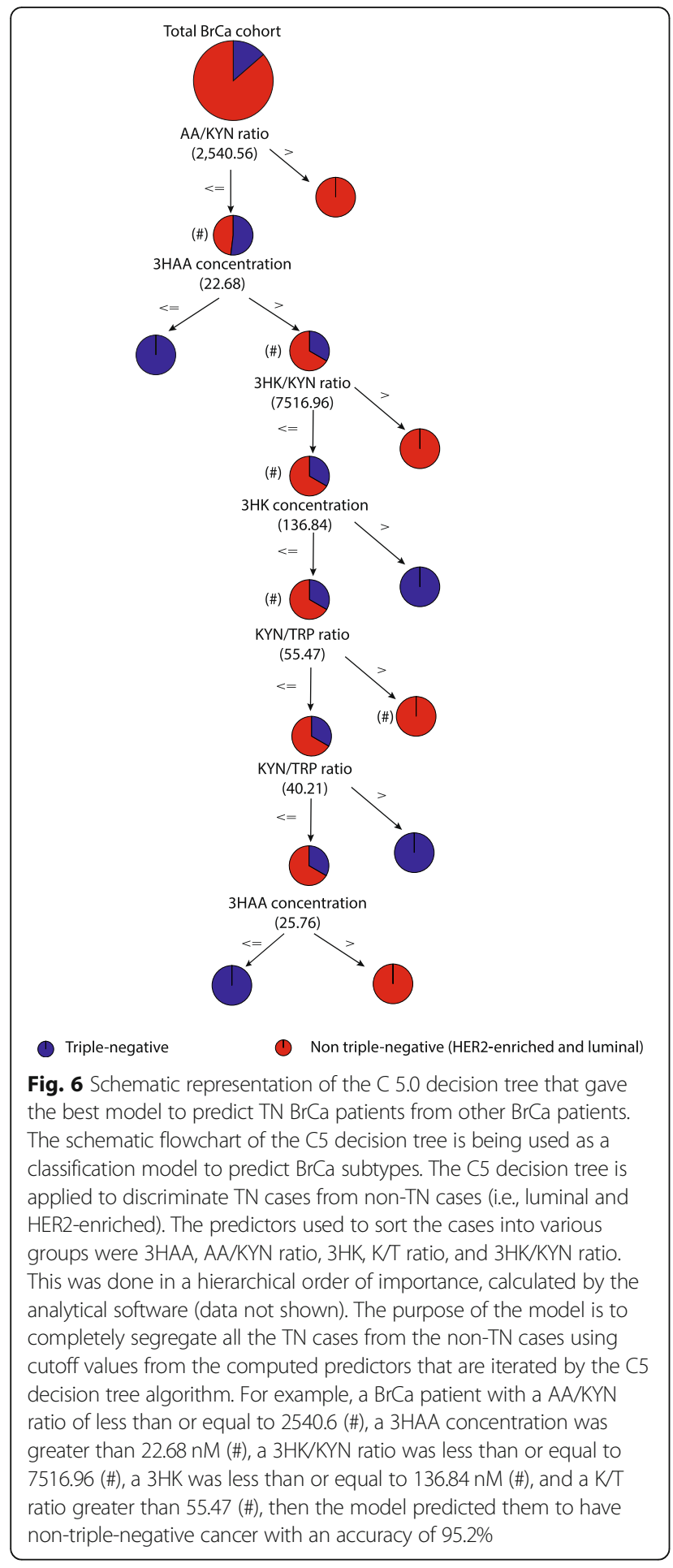

non-TN (luminal and HER2). The new predictors of importance were 3HAA (0.43), AA/KYN (0.23), 3HK (0.15), K/T ratio (0.11), and $3 \mathrm{HK} / \mathrm{KYN}(0.08)$. Our final model, using a C5.0 decision tree, provided the best subtype prediction for TN with a sensitivity of $95.2 \%$ and 63.2\% in the training and test sets, respectively (Fig. 6). This model was $44 \%$ more accurate than randomly allocating observations to $\mathrm{TN}$ or non-TN groups (i.e., lifts for $\mathrm{TN} \mathrm{BrCa}$ cases and non- $\mathrm{TN} \mathrm{BrCa}$ cases were 1.4; Fig. 6).

\section{Discussion}

Although the KP has emerged as a key immunotherapeutic target for cancer, the role of this pathway in $\mathrm{BrCa}$ has been relatively understudied. We have sought to fill this gap by comprehensively examining the KP in each major BrCa subtype, which has resulted in some novel findings. Our first key finding is that the KP is more highly dysregulated in the aggressive HER2-enriched and TN BrCa subtypes. Our second key finding is that the enzymes KMO and KYNU are highly upregulated in the aggressive HER2-enriched and TN BrCa subtypes. These results possibly provide a link between highly proliferative, metastatic lesions and KP dysregulation, as excessive $\mathrm{KMO}$ or KYNU activity increases the production of immunosuppressive metabolites. Our clinical and in vitro data has also confirmed the important role played by IDO1, particularly in the TN subtype, in producing excess KYN that fuels the KP downstream. We have also observed, for the first time, that $\mathrm{TN} \mathrm{BrCa}$ cells are capable of producing the immunosuppressive KP metabolite 3HAA. Significantly, our study shows that serum KP profiles can successfully discriminate TN $\mathrm{BrCa}$ patients from other BrCa patients.

Our data has demonstrated that clinical samples from TN BrCa patients had much higher IDO1 expression. We hypothesized that a number of upstream genes associated with the TN BrCa subtype could be upregulating IDO1 expression. In particular, gene profiling of TN breast tumors revealed that STAT3 and NF- $k B$ were highly activated. These two genes have been shown to crosstalk, potentiating IDO1 upregulation in myeloidderived suppressor cells [32, 33]. Yu et al. further demonstrated in a mouse model that the disruption of the STAT3-NF-kB-IDO1 axis using a small-molecule inhibitor of STAT3 led to a significant downregulation of IDO1 expression in tumor-suppressing myeloid cells and a reduction in the size of $\mathrm{BrCa}$ tumors [34]. Another potentially significant gene cascade is the cytokine signaling 3 suppressor (SOCS3) [35], one of the major negative feedback regulators of inflammatory cytokine signaling pathways such as the JAK/STAT signaling pathway [36] and a known suppressor of IDO1 [37, 38]. TN BrCa has low expression of SOCS3. Fallarino et al. and Pallotta et al. have shown that the induction of SOCS3 in IDO1-positive dendritic cells inhibits IDO1 transcription [37] and targets IDO1 protein for proteasome degradation [38]. Hence, low SOCS3 expression is a probable factor in the enhanced IDO1 expression seen in TN breast tumors. High expression of the aryl hydrocarbon receptor (AhR) in $\mathrm{TN} \mathrm{BrCa}$ may provide 
another compelling explanation of high IDO1 expression. AhR is a master environment-responsive immune regulator, which has been found to be highly expressed in $\mathrm{TN} \mathrm{BrCa}$ cells $[39,40]$. AhR not only directly increases IDO1 expression [41] but is also responsible for enzymatic IDO1 phosphorylation during posttranslational modification [42]. It is possible to speculate that the above genes may work in tandem to shift the balance towards the induction of IDO1 expression in TN BrCa.

Our in vitro data (Fig. 2d) have shown that the TN $\mathrm{BrCa}$ cell line, MDA-MB-468, has the highest IDO1 expression compared to cell lines of other BrCa subtypes. We have also found that induction of IDO1 by IFN- $\gamma$ results in markedly increased $\mathrm{KYN}$ production in $\mathrm{TN} \mathrm{BrCa}$ cell lines, but not in other $\mathrm{BrCa}$ cell lines relative to the untreated control (Fig. 2e and Supplementary Fig. 1D). Considering that KYN is an AhR ligand [43], this suggests a possible autocrine feedback loop between AhR and IDO1 that impairs immune system function, particularly in $\mathrm{TN} \mathrm{BrCa}$.

Crucially, our finding that high IDO expression is specific to TN and not other BrCa subtypes may partially explain the limited efficacy of IDO1 inhibitors in clinical trials. The 2018 phase 3 clinical trial (NCT02752074) that examined the effectiveness of combining an IDO1 inhibitor, epacadostat, with the checkpoint inhibitor pembrolizumab found that melanoma patient progression-free survival was not improved. Other clinical trials have successfully used patient pre-treatment screening to ensure an "on-target" treatment cohort. For example, anti-PD-L1 immunohistochemistry screening identified lung cancer patients most likely to benefit from pembrozlizumab treatment [44]. Considering the success of this screening strategy, the inclusion of $\mathrm{KP}$ profile screening of cancer patients may improve treatment efficacy in future trials of IDO1 inhibitors. More specifically, our study suggests that $\mathrm{TN} \mathrm{BrCa}$ patients are most likely to benefit in future clinical trials involving IDO1 inhibitors.

Despite the focus on IDO1, there is growing evidence demonstrating that IDO1 is not the only KP enzyme that produces immune modulatory metabolites. In particular, the downstream KP metabolites 3HK and 3HAA have been shown to modulate $\mathrm{T}$ cell populations. Both Fallarino et al. and Zaher et al. have reported that $3 \mathrm{HK}$ inhibits $\mathrm{CD} 4+\mathrm{T}$ cell proliferation [12, 13], and Zaher et al. have further shown that $3 \mathrm{HK}$ promoted the proliferation of $\mathrm{CD} 25+\mathrm{T}$ cells [13]. Another potent immunosuppressive KP metabolite, 3HAA, has also been shown to inhibit CD8+ $\mathrm{T}$ cell proliferation [45]. In addition to the immunotoxic effect on $\mathrm{T}$ cell proliferation, Platten et al. have shown that $3 \mathrm{HK}$ and $3 \mathrm{HAA}$ can inhibit the production of pro-inflammatory cytokines by CD4+ T cells [46]. Our study has shown that the 3HKproducing enzyme, $\mathrm{KMO}$, is highly elevated in $\mathrm{BrCa}$, especially in HER2-enriched $\mathrm{BrCa}$ tissue, concordant with the high serum level of $3 \mathrm{HK}$ detected in people with $\mathrm{BrCa}$ (Fig. 3a-c). In agreement with our study, the global quantitative proteomic mapping study examining $\mathrm{BrCa}$ subtypes identified $\mathrm{KMO}$ as a significantly upregulated protein in HER2-enriched $\mathrm{BrCa}$ subtype. The molecular mechanisms underlying enhanced KMO expression in HER2-enriched, however, need further investigation.

Also, elevated in HER2-enriched BrCa tissue was the enzyme KYNU, which produces both 3HAA and AA. Our ex vivo metabolite profiling data further revealed that KYNU preferentially produces AA over 3HAA, suggesting that downstream KP metabolites may have a role in $\mathrm{BrCa}$ aggressiveness. To address whether the downstream activity of KMO and KYNU results from IDO1 induction, we examined de novo KP metabolite biosynthesis following IDO1 induction by IFN $-\gamma$ in $\mathrm{BrCa}$ cell lines. These data showed that luminal and HER2enriched $\mathrm{BrCa}$ cells share a similar profile favoring $3 \mathrm{HK}$ production, whereas TN cells have a preference for 3HAA production, as illustrated by the radar chart (Fig. 5f). Considering the potent immune-suppressive effects of 3HAA, this could be a significant factor in the relative aggressiveness and metastatic potential of TN $\mathrm{BrCa}$. High 3HAA production may also account for the low levels of 3HK in TN BrCa cells (Fig. 3e) as 3HK can be rapidly metabolized to 3HAA (Fig. 5f).

While our in vitro data shows a higher 3HAA concentration in $\mathrm{TN}$ BrCa cells, the concentration of 3HAA was lower in $\mathrm{TN} \mathrm{BrCa}$ patient sera. Potential reasons that may explain this include the fact that 3HAA is a highly reactive compound that is auto-oxidized more rapidly, as compared to AA in aqueous conditions (serum) [47]. Additionally, the conversion of AA to 3HAA is dependent on milieu $\mathrm{pH}$ and iron availability [48], and it is interesting to note that the aggressiveness of the TN subtype has been shown to be related to the balance of iron-regulating genes that lead to tumor iron accumulation [49]. Considering that both TN and HER2-enriched $\mathrm{BrCa}$ feature a more dysregulated and immunosuppressive KP compared to the less aggressive luminal subtype, it would be interesting to assess the inhibition of KMO and KYNU, which lead to AA and 3HAA, respectively, in animal models of TN breast cancer.

The application of classification modeling for biomarker discovery has become increasingly popular. In $\mathrm{BrCa}$, serum TRP and KYN levels have been suggested as biomarkers for monitoring treatment efficacy $[18,50]$. Hence, we explored if our extensive $\mathrm{BrCa} \mathrm{KP}$ profiling 
data may have additional biomarker potential for clinical translation. Using an unbiased machine learning approach, we initially attempted to discriminate $\mathrm{BrCa}$ subtypes from $\mathrm{HC}$. We observed that KP metabolites were not able to discriminate $\mathrm{HC}$ from $\mathrm{BrCa}$ cases because the KP can be dysregulated by many inflammatory conditions. Hence, we developed models with a prognostic focus that excluded healthy controls as potential confounders. Our final model (Fig. 6) demonstrated a strong discriminating ability to identify $\mathrm{TN} \mathrm{BrCa}$ with up to 95.2\% accuracy, which approximates the sensitivity achieved by current clinically used biomarkers to identify luminal and HER2-enriched BrCa patients (93.7-97\% and $80-96.2 \%$, respectively) [51, 52]. Interestingly, age, a well-known risk factor for $\mathrm{BrCa}$, was no longer an important factor when predicting $\mathrm{BrCa}$ subtype, highlighting the applicability of using KP predictors in assessing $\mathrm{BrCa}$ prognosis and also suggesting a potentially dependent relationship between the $\mathrm{KP}$ and $\mathrm{BrCa}$ pathology, independent of age. This approach demonstrates the value of $\mathrm{KP}$ as a biomarker for targeted therapies in breast cancer and as a surrogate marker for intrinsic subtype prediction.

Our study has limitations. As a cross-sectional study, it is not possible to assess KP metabolites in terms of TN risk or survival that would be possible with a longitudinal cohort. Such data could strengthen the case that downstream KP enzymes, KMO and KYNU in particular, play a significant role in mediating $\mathrm{BrCa}$ aggressiveness, thereby suggesting new potential therapeutic approaches in $\mathrm{BrCa}$. As the $\mathrm{HC}$ group in our clinical cohort was significantly younger compared to $\mathrm{BrCa}$ groups, age might have been a confounding factor. However, as discussed above, our unbiased machine learning method indicated that age was not a significant factor in discriminating the TN subtype. Finally, the lack of matching immune profile data limits our ability to assess the interplay between the immune system and the KP in our clinical cohorts.

\section{Conclusion}

We have demonstrated, for the first time, that the downstream KP enzymes KMO and KYNU are hyperactive in more aggressive $\mathrm{BrCa}$ subtypes, leading to enhanced production of the immunosuppressive metabolites AA and 3HAA. Thus, we have demonstrated that the welldescribed role played by the KP in mediating cancer immune tolerance extends beyond IDO1, potentially identifying KMO and KYNU inhibitors as new therapeutic $\mathrm{BrCa}$ targets. Our data further suggests that $\mathrm{KP}$ metabolite profiling has potential as a biomarker in $\mathrm{BrCa}$ subtyping, as our study successfully discriminated TN $\mathrm{BrCa}$ from other BrCa subtypes.

\section{Supplementary information}

Supplementary information accompanies this paper at https://doi.org/10. 1186/s13058-020-01351-1.

Additional file 1: Figure S1. IDO1, KMO and KYNU expression in luminal and TN BrCa cell lines. IDO1, KMO and KYNU mRNA expression were quantified using qPCR after after $24 \mathrm{hrs} \mathrm{IFN-} \gamma$ treatment $(n=3$, in triplicate). a IDO1 mRNA expression is highly elevated in TN BrCa cell lines by an approximately 10-fold higher as compared to luminal $\mathrm{BrCa}$ cell lines. b KMO mRNA expression is induced in luminal BrCa cell line (approximately 2-fold change) and $\mathrm{TN}$ BrCa cell lines (approximately 10-fold change) c KYNU mRNA expression increased only in TN BrCa cell lines except MDA-MB-157 (approxximately to 1.5 to 2-fold change). d Only TN BrCa cell lines showed singificant IDO1 activity as reflected by $\mathrm{K} T$ ratio after 48 hrs IFN- $\gamma$ treatment. e There is a marked decrease in KMO activity in TN BrCa cell lines after 48 hrs IFN- $\gamma$ treatment as shown by decreased $3 \mathrm{HK} / \mathrm{K}$ ratio after $48 \mathrm{hrs}$ IFN- $\gamma$ treatment. However, there is no difference in $\mathrm{KMO}$ activity between the IFN- $\gamma$ treatment and control of luminal $\mathrm{BrCa}$ cell line. $f$ There is no difference in the KYNU activity along the minor KP sub-branch that leads to AA (as judged by AA/K ratio) in BrCa cell lines after 48 hrs IFN- $\gamma$ treatment whereas, g KYNU activity along the major KP sub-branch leading to 3HAA (as shown by $3 \mathrm{HAA} / \mathrm{K}$ ratio) is upregulated in TN BrCa cells lines after 48 hrs IFN- $\gamma$ treatment. KP metabolite analysis was performed using UHPLC. * and \#, $p<0.05$; ${ }^{* *}$ and \#\#, $p<0.01$; ${ }^{* *}$ and $\# \# \#$ " $p<0.001 ;{ }^{* * * *}$ and \#\#\#, $P<0.0001$

Additional file 2: Table S1. Realtime PCR primer details.

\section{Abbreviations}

BrCa: Breast cancer; KP: Kynurenine pathway; TN: Triple-negative; IDO1: Indoleamine-2,3-dioxygenase 1; TRP: Tryptophan; 3HK: 3-

Hydroxykynurenine; AA: Anthranilic acid; 3HAA: 3-Hydroxyanthranilic acid; KYN: Kynurenine; KMO: Kynurenine monooxygenase; HC: Healthy control; METABRIC: Molecular Taxonomy of Breast Cancer International Consortium; KATs: Kynurenine aminotransferase; KYNU: Kynureninase; SOCS3: Cytokine signaling 3 suppressor; AhR: Aryl hydrocarbon receptor

\section{Acknowledgements}

This paper was professionally edited by Red Fern Communication. The authors would like to thank our cancer consumers, Ms. Elizabeth Klaes from Breast Cancer Network Australia and Ms. Marina van Leeuwen and Mr. Rob Ferguson from Macquarie University's Cancer Research Consumer Advisory Group for their valuable feedback to the research priorities of this study and support with the dissemination of research findings to the community.

\section{Authors' contributions}

B.H, C.K.L, and G.J.G conceptualized and designed the study. B.H, C.K.L, and D.B.L drafted and wrote the manuscript. B.H and C.K.L carried out and analyzed the KP metabolomics data. B.H and V.X.T performed the immunohistochemistry and analyzed the results. B.H, G.J.G, and L.G collected and organized the clinical samples and data. H.H.M and P.M performed the statistical analysis on the METABRIC clinical data. A.A.B completed the statistical analysis and classification modeling. All authors contributed to the data interpretation and reviewed and approved the final version of the manuscript. B.H and T.S optimized the immunohistochemistry.

\section{Funding}

This study was supported by a research grant (Scott Canner Young Researcher grant) from Tour de Cure Foundation and a research donation from the philanthropy group, Fight on the Beaches. Prof Guillemin is funded by the National Health and Medical Research Council (NHMRC) and Macquarie University. Prof. Muscato is supported by the Australian Research Council (ARC) Future Fellowship FT12010060 (http://arc.gov.au/). His work is partially funded by the ARC Discovery Project (DP120102576) and Cancer Institute of New South Wales, Australia (13/DATA/1-03). The funders had no role in the study design, data collection, and analysis; decision to publish; or preparation of the manuscript.

\section{Availability of data and materials}

The METABRIC microarray dataset used in this study is available at the European Genome-Phenome Archive at http://www.ebi.ac.uk/ega, under the 
accession number EGAS00000000083 [22]. All remaining data and materials are available from the authors upon reasonable request.

\section{Ethics approval and consent to participate}

The use of patient sera and tissue for this study was approved by the Macquarie University Human Research Ethics Committee (5201600401). The use of METABRIC data for research was approved by the Human Ethics Research Committee of the University of Newcastle, Australia (Ref: H-2013-0277).

\section{Consent for publication}

Not applicable.

\section{Competing interests}

The authors declare that they have no competing interests.

\section{Author details}

${ }^{1}$ Department of Biomedical Sciences, Faculty of Medicine and Health Sciences, Macquarie University, Sydney, Australia. ${ }^{2}$ Faculty of Sciences and Engineering, Macquarie University, Sydney, Australia. ${ }^{3}$ School of Environmental and Life Sciences, The University of Newcastle, Callaghan, Australia. ${ }^{4}$ The Strathfield Breast Centre, Strathfield, Australia. ${ }^{5}$ Bioanalytical Mass Spectrometry Facility, University of New South Wales, Sydney, Australia. ${ }^{6}$ School of Electrical Engineering and Life Sciences, The University of Newcastle, Callaghan, Australia.

\section{Received: 28 July 2020 Accepted: 5 October 2020}

\section{Published online: 27 October 2020}

\section{References}

1. Global Burden of Disease Cancer C, Fitzmaurice C, Allen C, Barber RM, Barregard L, Bhutta ZA, et al. Global, regional, and national cancer incidence, mortality, years of life lost, years lived with disability, and disability-adjusted lifeyears for 32 cancer groups, 1990 to 2015: a systematic analysis for the Global Burden of Disease Study. JAMA Oncol. 2017;3(4):524-48.

2. Redig AJ, McAllister SS. Breast cancer as a systemic disease: a view of metastasis. J Intern Med. 2013;274(2):113-26.

3. Drake CG, Lipson EJ, Brahmer JR. Breathing new life into immunotherapy: review of melanoma, lung and kidney cancer. Nat Rev Clin Oncol. 2014 11(1):24-37.

4. Stanton SE, Disis ML. Clinical significance of tumor-infiltrating lymphocytes in breast cancer. J Immunother Cancer. 2016:4:59.

5. Bates GJ, Fox SB, Han C, Leek RD, Garcia JF, Harris AL, et al. Quantification of regulatory $T$ cells enables the identification of high-risk breast cancer patients and those at risk of late relapse. J Clin Oncol. 2006;24(34):5373-80.

6. Pusztai L, Karn T, Safonov A, Abu-Khalaf MM, Bianchini G. New strategies in breast cancer: immunotherapy. Clin Cancer Res. 2016;22(9):2105-10.

7. Prendergast GC. Immune escape as a fundamental trait of cancer: focus on IDO. Oncogene. 2008;27(28):3889-900

8. Prendergast GC, Malachowski WP, DuHadaway JB, Muller AJ. Discovery of IDO1 inhibitors: from bench to bedside. Cancer Res. 2017;77(24):6795-811.

9. Lob S, Konigsrainer A, Rammensee HG, Opelz G, Terness P. Inhibitors of indoleamine-2,3-dioxygenase for cancer therapy: can we see the wood for the trees? Nat Rev Cancer. 2009;9(6):445-52.

10. Munn DH, Mellor AL. Indoleamine 2,3 dioxygenase and metabolic control of immune responses. Trends Immunol. 2013;34(3):137-43.

11. Uyttenhove C, Pilotte L, Theate I, Stroobant V, Colau D, Parmentier N, et al. Evidence for a tumoral immune resistance mechanism based on tryptophan degradation by indoleamine 2,3-dioxygenase. Nat Med. 2003:9(10):1269-74.

12. Fallarino F, Grohmann U, Vacca C, Bianchi R, Orabona C, Spreca A, et al. T cell apoptosis by tryptophan catabolism. Cell Death Differ. 2002;9(10):1069-77.

13. Zaher SS, Germain C, Fu H, Larkin DF, George AJ. 3-Hydroxykynurenine suppresses CD4+ T-cell proliferation, induces T-regulatory-cell development, and prolongs corneal allograft survival. Invest Ophthalmol Vis Sci. 2011:52(5): 2640-8

14. Godin-Ethier J, Pelletier S, Hanafi LA, Gannon PO, Forget MA, Routy JP, et al. Human activated T lymphocytes modulate IDO expression in tumors through Th1/Th2 balance. J Immunol. 2009;183(12):7752-60.

15. Puccetti P, Fallarino F, Italiano A, Soubeyran I, MacGrogan G, Debled M, et al. Accumulation of an endogenous tryptophan-derived metabolite in colorectal and breast cancers. PLoS One. 2015;10(4):e0122046.
16. Sakurai K, Amano S, Enomoto K, Kashio M, Saito Y, Sakamoto A, et al. Study of indoleamine 2,3-dioxygenase expression in patients with breast cancer. Gan to kagaku ryoho Cancer Chemotherapy. 2005;32(11):1546-9.

17. Juhasz C, Nahleh Z, Zitron I, Chugani DC, Janabi MZ, Bandyopadhyay S, et al. Tryptophan metabolism in breast cancers: molecular imaging and immunohistochemistry studies. Nucl Med Biol. 2012;39(7):926-32.

18. Lyon DE, Walter JM, Starkweather AR, Schubert CM, McCain NL. Tryptophan degradation in women with breast cancer: a pilot study. BMC Research Notes. 2011:4:156.

19. Mansfield AS, Heikkila PS, Vaara AT, von Smitten KA, Vakkila JM, Leidenius $\mathrm{MH}$. Simultaneous Foxp3 and IDO expression is associated with sentinel lymph node metastases in breast cancer. BMC Cancer. 2009;9:231.

20. Sakurai K, Fujisaki S, Nagashima S, Maeda T, Shibata M, Gonda K, et al. Analysis of indoleamine 2, 3-dioxygenase expression in breast cancer patients with bone metastasis. Gan to kagaku ryoho Cancer \& chemotherapy. 2012;39(12):1776-8.

21. Jin $\mathrm{H}$, Zhang $Y$, You $H$, Tao $X$, Wang $C$, Jin $G$, et al. Prognostic significance of kynurenine 3-monooxygenase and effects on proliferation, migration, and invasion of human hepatocellular carcinoma. Sci Rep. 2015:5:10466.

22. Curtis C, Shah SP, Chin SF, Turashvili G, Rueda OM, Dunning MJ, et al. The genomic and transcriptomic architecture of 2,000 breast tumours reveals novel subgroups. Nature. 2012;486(7403):346-52.

23. Bustin SA, Benes V, Garson JA, Hellemans J, Huggett J, Kubista M, et al. The MIQE guidelines: minimum information for publication of quantitative realtime PCR experiments. Clin Chem. 2009;55(4):611-22.

24. Lim CK, Bilgin A, Lovejoy DB, Tan V, Bustamante S, Taylor BV, et al. Kynurenine pathway metabolomics predicts and provides mechanistic insight into multiple sclerosis progression. Sci Rep. 2017;7:41473.

25. Venables WN, Ripley BD, Venables WN. Modern applied statistics with S. New York: Springer; 2002.

26. Han J, Kamber M, Pei J. Data mining: concepts and techniques, 3rd edition. Mor Kauf D. 2012:1-703.

27. Hastie T, Tibshirani R, Friedman JH, Friedman JH. The elements of statistical learning: data mining, inference, and prediction. 2nd ed. New York: Springer-Verlag New York; 2009. xxii, 745 p. p.

28. Fox J, Weisberg S, Fox J. An R companion to applied regression. 2nd ed. Thousand Oaks, Calif.: SAGE Publications; 2011. xxii, 449 p. p.

29. Walker AK, Budac DP, Bisulco S, Lee AW, Smith RA, Beenders B, et al. NMDA receptor blockade by ketamine abrogates lipopolysaccharide-induced depressivelike behavior in C57BL/6J mice. Neuropsychopharmacol. 2013;38(9):1609-16.

30. Baran H, Schwarcz R. Evidence for the preferential production of 3hydroxyanthranilic acid from anthranilic acid in the rat brain. Adv Exp Med Biol. 1991;294:485-8

31. Majewski M, Kozlowska A, Thoene M, Lepiarczyk E, Grzegorzewski WJ. Overview of the role of vitamins and minerals on the kynurenine pathway in health and disease. J Physiol Pharmacol. 2016;67(1):3-19.

32. McDaniel JM, Varley KE, Gertz J, Savic DS, Roberts BS, Bailey SK, et al. Genomic regulation of invasion by STAT3 in triple negative breast cancer. Oncotarget. 2017:8(5):8226-38.

33. Peddi PF, Ellis MJ, Ma C. Molecular basis of triple negative breast cancer and implications for therapy. Int J Breast Cancer. 2012;2012:217185.

34. Yu J, Wang Y, Yan F, Zhang P, Li H, Zhao H, et al. Noncanonical NF-kB activation mediates STAT3-stimulated IDO upregulation in myeloid-derived suppressor cells in breast cancer. J Immunol. 2014;193(5):2574-86.

35. Kim G, Ouzounova M, Quraishi AA, Davis A, Tawakkol N, Clouthier SG, et al. SOCS3-mediated regulation of inflammatory cytokines in PTEN and p53 inactivated triple negative breast cancer model. Oncogene. 2015;34(6):671-80.

36. Iwahori K, Serada S, Fujimoto M, Nomura S, Osaki T, Lee CM, et al. Overexpression of SOCS3 exhibits preclinical antitumor activity against malignant pleural mesothelioma. Int J Cancer. 2011;129(4):1005-17.

37. Fallarino F, Orabona C, Vacca C, Bianchi R, Gizzi S, Asselin-Paturel C, et al. Ligand and cytokine dependence of the immunosuppressive pathway of tryptophan catabolism in plasmacytoid dendritic cells. Int Immunol. 2005; 17(11):1429-38.

38. Pallotta MT, Orabona C, Volpi C, Grohmann U, Puccetti P, Fallarino F. Proteasomal degradation of indoleamine 2,3-dioxygenase in CD8 dendritic cells is mediated by suppressor of cytokine signaling 3 (SOCS3). Int J Tryptophan Res. 2010;3:91-7.

39. Romagnolo DF, Papoutsis AJ, Laukaitis C, Selmin OI. Constitutive expression of AhR and BRCA-1 promoter CpG hypermethylation as biomarkers of ERanegative breast tumorigenesis. BMC Cancer. 2015;15:1026. 
40. Salisbury TB, Tomblin JK, Primerano DA, Boskovic G, Fan J, Mehmi I, et al. Endogenous aryl hydrocarbon receptor promotes basal and inducible expression of tumor necrosis factor target genes in MCF-7 cancer cells. Biochem Pharmacol. 2014:91(3):390-9.

41. Vacher S, Castagnet P, Chemlali W, Lallemand F, Meseure D, Pocard M, et al. High AHR expression in breast tumors correlates with expression of genes from several signaling pathways namely inflammation and endogenous tryptophan metabolism. PLoS One. 2018;13(1):e0190619.

42. Bessede A, Gargaro M, Pallotta MT, Matino D, Servillo G, Brunacci C, et al. Aryl hydrocarbon receptor control of a disease tolerance defence pathway. Nature. 2014:511(7508):184-90.

43. Opitz CA, Litzenburger UM, Sahm F, Ott M, Tritschler I, Trump S, et al. An endogenous tumour-promoting ligand of the human aryl hydrocarbon receptor. Nature. 2011;478(7368):197-203.

44. Ancevski Hunter K, Socinski MA, Villaruz LC. PD-L1 testing in guiding patient selection for PD-1/PD-L1 inhibitor therapy in lung cancer. Mol Diagn Ther. 2018;22(1):1-10.

45. Weber WP, Feder-Mengus C, Chiarugi A, Rosenthal R, Reschner A, Schumacher $R$, et al. Differential effects of the tryptophan metabolite 3-hydroxyanthranilic acid on the proliferation of human CD8+ T cells induced by TCR triggering or homeostatic cytokines. Eur J Immunol. 2006;36(2):296-304.

46. Platten M, Ho PP, Youssef S, Fontoura P, Garren H, Hur EM, et al. Treatment of autoimmune neuroinflammation with a synthetic tryptophan metabolite. Science. 2005;310(5749):850-5.

47. Dykens JA, Sullivan SG, Stern A. Oxidative reactivity of the tryptophan metabolites 3-hydroxyanthranilate, cinnabarinate, quinolinate and picolinate. Biochem Pharmacol. 1987;36(2):211-7.

48. Darlington LG, Forrest CM, Mackay GM, Smith RA, Smith AJ, Stoy N, et al. On the biological importance of the 3-hydroxyanthranilic acid: anthranilic acid ratio. Int J Tryptophan Res. 2010;3:51-9.

49. Miller LD, Coffman LG, Chou JW, Black MA, Bergh J, D’Agostino R Jr, et al. An iron regulatory gene signature predicts outcome in breast cancer. Cancer Res. 2011;71(21):6728-37.

50. Sakurai K, Fujisaki S, Nagashima S, Maeda T, Shibata M, Gonda K, et al. Indoleamine 2, 3-dioxygenase activity during chemotherapy or trastuzumab therapy in patients with breast cancer. Gan to kagaku ryoho Cancer Chemotherapy. 2012;39(12):1791-3.

51. Chen X, Yuan Y, Gu Z, Shen K. Accuracy of estrogen receptor, progesterone receptor, and HER2 status between core needle and open excision biopsy in breast cancer: a meta-analysis. Breast Cancer Res Treat. 2012;134(3):957-67.

52. Dekker TJ, Smit VT, Hooijer GK, Van de Vijver MJ, Mesker WE, Tollenaar RA, et al. Reliability of core needle biopsy for determining ER and HER2 status in breast cancer. Ann Oncol. 2013;24(4):931-7.

\section{Publisher's Note}

Springer Nature remains neutral with regard to jurisdictional claims in published maps and institutional affiliations.

Ready to submit your research? Choose BMC and benefit from:

- fast, convenient online submission

- thorough peer review by experienced researchers in your field

- rapid publication on acceptance

- support for research data, including large and complex data types

- gold Open Access which fosters wider collaboration and increased citations

- maximum visibility for your research: over $100 \mathrm{M}$ website views per year

At BMC, research is always in progress.

Learn more biomedcentral.com/submissions 